\section{RMD Open}

Rheumatic \&

Musculoskeletal Diseases

\title{
5-year follow-up of spinal and sacroiliac MRI abnormalities in early axial spondyloarthritis: data from the DESIR cohort
}

To cite: Madari Q, Sepriano A, Ramiro $\mathrm{S}$, et al. 5-year followup of spinal and sacroiliac MR abnormalities in early axial spondyloarthritis: data from the DESIR cohort. RMD Open 2020;6:e001093. doi:10.1136/ rmdopen-2019-001093

- Additional material is published online only. To view, please visit the journal online (http://dx.doi.org/10.1136/ rmdopen-2019-001093).

Received 28 August 2019 Revised 13 December 2019 Accepted 5 January 2020

Check for updates

(C) Author(s) (or their employer(s)) 2020. Re-use permitted under CC BY-NC. No commercial re-use. See rights and permissions. Published by BMJ.

For numbered affiliations see end of article.

Correspondence to Dr Floris A van Gaalen; f.a.van_gaalen@lumc.de

\section{ABSTRACT}

Objective To study changes on MRI of the spine and sacroiliac joint (SIJ) in early axial spondyloarthritis (axSpA) over time.

Methods In the Devenir des Spondyloarthropathies Indifférenciées Récentes cohort, MRI-spine and MRI-SIJ at baseline and 2 and 5 years were scored by central readers for bone marrow oedema (BME), fatty lesions, erosions, sclerosis, ankylosis and spinal bone spurs. The average mean number of lesions was reported or the agreement of $\geq 2$ out of 3 readers for binary outcomes. Net progression was calculated by subtracting the patients that 'improved' from those that 'worsened' divided by the total number of patients.

Results Over 5 years, in 155 patients with axSpA (mean age 33.5 (SD 8.9) years, symptom duration $1.4(0.8)$ years, $63 \%$ human leucocyte antigen+, $14 \%$ modified New York+), BME on MRI-SIJ decreased by a mean Spondyloarthritis Research Consortium of Canada score of 1.4 (SD 6.5) ( $p=0.009)$. The largest BME decrease was observed in patients using biological disease-modifying antirheumatic drugs at 5 years. Spinal BME increased by $0.3(4.6)(p=0.41)$. Fatty lesions and/or erosions on MRISIJ increased by a mean of 1.0 (SD 2.6) $(p<0.001)$. Spinal fatty lesions and/or erosions increased by 0.2 (SD 0.5) $(p<0.001)$. Compared with baseline, at 5 years, $7.3 \%$ less patients had BME on MRI-SIJ according to the Assessment of Spondyloarthritis International Society definition, while $6.6 \%$ more patients had $\geq 5$ fatty lesions and/or erosions. At 5 years, $0.7 \%$ less patients had $\geq 5$ spinal BME lesions and $0.7 \%$ less patients had $\geq 5$ spinal fatty lesions. Conclusion Over 5 years, BME on MRI-SIJ decreased and spinal BME remained similar, but numerically, little progression of structural lesions on MRI of the SIJ and spine was seen.

\section{INTRODUCTION}

Axial spondyloarthritis (axSpA) is a chronic inflammatory rheumatic disease affecting the axial skeleton. When definite signs of sacroiliitis are seen on conventional radiography, patients can be diagnosed with radiographical

\section{Key messages}

What is already known?

- Outside of clinical trials, little is known of the course of spondyloarthritis-associated MRI abnormalities in the spine and sacroiliac joints (SIJs).

What does this study add?

- In patients in the Devenir des Spondyloarthropathies Indifférenciées Récentes cohort over 5 years, bone marrow oedema (BME) on MRI-SIJ decreased significantly, with the largest decrease observed in patients using biological disease-modifying antirheumatic drugs at 5 years.

- BME in the spine was uncommon but remained similar over 5 years.

- In line with previous data on radiographical progression from the cohort, over 5 years, little progression in structural MRI lesions in spine and SIJs was seen.

How might this impact on clinical practice?

- This suggest that in patients with early axial spondyloarthritis (axSpA), a repeated MRI to detect progression of structural lesions with high specificity for axSpA in the first years of disease is of limited value.

axSpA or ankylosing spondylitis (AS). AxSpA is called non-radiographical axSpA when no definite abnormalities can be detected on radiographs of the sacroiliac joint (SIJ).

MRI gained interest due to its ability to visualise both inflammation and structural changes in the axial skeleton. On MRI of the SIJ (MRI-SIJ), subchondral bone marrow oedema (BME) is thought to reflect active inflammation, while MRI-detectable sclerosis, erosions, fatty lesions, spinal bone spurs and sacroiliac ankylosis reflect structural damage. ${ }^{1}$

In particular, detection of BME on MRI-SIJ is used in diagnosis and has become part of the current classification criteria for axSpA. ${ }^{23}$ 
Given that sacroiliac BME may also occur in other conditions and even in healthy individuals, assessment of structural changes in the SIJ,to enhance the diagnostic utility of MRI is a subject of active research. ${ }^{4}$ For example, presence of at least three fatty lesions or at least five fatty lesions and/ or erosions on MRI-SIJ has a reported $>90 \%$ specificity for early axSpA. The same study showed that at least five inflammatory BME lesions or at least five fatty lesions on MRI-spine have a similarly high specificity for axSpA. ${ }^{56}$

MRI lesions may also have potential prognostic value as in patients with AS in clinical trials, vertebral corner BME is associated with subsequent radiographical progression, with one study also showing an association between fatty lesions and progression. ${ }^{7}$ Strikingly, while the association between MRI lesion and radiographical damage is far from clear, spinal MRI outcomes are already used to study the effect of treatment. For example, although it was acknowledged that the significance of the finding was unclear, the authors of a study on the 2-year effect of secukinumab treatment on spinal MRI findings in AS did believe it was worth reporting that the observed progression of spinal fatty lesion compared favourable to previous studies on tumour necrosis factor (TNF) blockers. ${ }^{8}$

With little known of the course of MRI abnormalities outside of clinical trials, we studied changes in spondyloarthritis (SpA)-associated inflammatory and structural lesions on both MRI of the SIJ and spine over 5 years in a cohort of patients with early disease.

\section{METHODS}

\section{Study population and design}

Five-year follow-up data from the Devenir des Spondyloarthropathies Indifférenciées Récentes (DESIR) cohort were used. The design and inclusion criteria of this cohort have been previously described in detail. ${ }^{9}$ In brief, the DESIR cohort is a French longitudinal prospective multicentre cohort study established between 2007 and 2010 that includes patients aged $\geq 18$ and $\leq 50$ years with inflammatory back pain for $\geq 3$ months but $\leq 3$ years and symptoms suggestive of axSpA according to the treating rheumatologist (with a level of confidence score of $\geq 5$ on a $0-10$ numerical rating scale in which $0=$ not suggestive and $10=$ very suggestive of $\mathrm{SpA}$ ).

Of the 708 patients included, the baseline average confidence of diagnosis was $6.8 \mathrm{SD} \pm 2.7$. Ninety-two per cent met at least one set of SpA classification criteria: modified New York criteria 26\%, Amor 79\%, European Spondyloarthropathy Study Group (ESSG) $78 \%$ and Assessment of Spondyloarthritis International Society (ASAS) axSpA criteria $70 \%{ }^{9}$

The database used for the current analysis was locked on 20 of June 2016.

\section{MRI assessments}

MRI-SIJ and MRI-spine were performed on a 1.0-1.5 T scanner providing T1-weighted (T1-w) turbo spin-echo and short tau inversion recovery (STIR) sequences. Coronal oblique plane was performed for the MRI-SIJ and sagittal plane for MRI-spine with a slice thickness of $4 \mathrm{~mm}$.

MRI-SIJ and MRI-spine were performed at baseline for all patients. By protocol, at 2 and 5 years of follow-up, MRIs were only performed in participating centres in Paris. The MRIs were evaluated independently by three central readers. Readers were blinded for all clinical and laboratory data, the chronology of images and the results from other imaging modalities.

\section{MRI-SIJ}

Readers scored the images for presence of BME lesions according to the ASAS definition for a positive MRI-SIJ ${ }^{2}$ and according to the Spondyloarthritis Research Consortium of Canada (SPARCC) scoring method (range 0-72). ${ }^{11}$ Fatty lesions, erosions, sclerosis and (partial) ankylosis are considered to be typical structural lesion for axSpA seen on MRI. ${ }^{1}$ The adapted SPARCC MRI-SIJ Structural Score by Weber $e t$ al was used for this study. ${ }^{12}$ This method is based on MRI T1-w images, anatomical slice selection and dichotomous scoring (lesion present/ absent) of six consecutive slices through the cartilaginous part of the SIJ, divided in quadrants. Erosions and fatty lesions were marked as present if seen on at least two consecutive slices and had a scoring range of 0-40 each. Ankylosis or partial ankylosis was considered present if seen on a single slice. It is assumed that partial ankylosis and ankylosis cannot occur simultaneously in a quadrant, and ankylosis always involves two quadrants; therefore, the corresponding scoring range is 0-24.

In the current study, sclerosis was added to the adapted SPARCC MRI-SIJ structural score and was defined as lowintensity or signal-free bands on both the T1-w and the STIR sequence extending at least $5 \mathrm{~mm}$ from the space between the SIJ. ${ }^{1}$ Sclerosis was scored in a similar way as the erosions and fatty lesions. The scoring range for the total number of structural lesions was defined as 0-144 since the number of fatty lesions, erosions, sclerosis and (partial) ankylosis was summed.

\section{MRI-SPINE}

Twenty-three vertebral units (VUs) were scored for BME lesions according to the Berlin method (range 0-69) ${ }^{13} 14$ and the spinal SPARCC (s-SPARCC) method (range 0-414), which is scored by quadrants per VU. ${ }^{11}$ In addition, MRIspine was also dichotomously defined as positive if anterior/posterior BME was present in $\geq 3$ sites of the spine according to the ASAS definition. ${ }^{15}$ For further evaluation, a cut-off of $\geq 5$ BME lesions was used. ${ }^{5}$ Spinal structural lesions seen on MRI were assessed by using the CanadaDenmark (CANDEN) scoring method. ${ }^{16}$ All 23 VUs were divided into quadrants. The CANDEN scoring method was slightly modified; only corner lesions (erosions, fatty lesions, bone spurs and ankylosis) were scored. Erosions scores were dichotomised (present yes/no) and scored when present on $\geq 1$ slice (range 0-92). Bone spurs and 
fatty lesions were scored when present on $\geq 1$ slice (range $0-92)$, and ankylosis was scored per two quadrants when present on $\geq 1$ slice (range $0-46$ ). The total number of structural lesions, compiled by spinal fatty lesions, erosions, bone spurs and ankylosis, has a range of 0-322.

For both MRI-SIJ and MRI-spine, continuous scores were reported as the mean number of lesions (average of three readers) and as the agreement of $\geq 2$ out of 3 readers for binary outcomes.

\section{Statistical analysis}

Statistical testing was performed to compare MRI inflammation and structural damage across different time points using paired t-test. For the binary outcomes, the proportion of patients with positive change (\% patients with worsening) and negative change (\% patients with improvement) over 5 years was determined using the cutoffs defined previously. The net percentage of change defines the number of patients with a positive change minus the number of patients with a negative change divided by the total number of patients included in the analysis. ${ }^{17}$ To assess reliability of continuous scores across the three readers, the intraclass correlation coefficients (ICCs) with 95\% CIs were calculated, and the following definition for interpreting ICC values was used: $<0.5$, $0.5-0.8,0.8-0.9$ and $>0.9$ were interpreted as respectively poor, moderate, good and excellent reliabilities. ${ }^{18}$

Statistical analysis was performed using STATA SE V.15.

\section{RESULTS}

\section{Baseline characteristics}

In the DESIR cohort, baseline MRIs were performed in 614 of the 708 included patients. Of these 614 patients, 167 were from centres which performed repeated MRIs at follow-up visits. Of these 167 patients, 140 had MRI follow-up at 2 years, and 155 had follow-up MRI at 5 years (figure 1A). In figure 1A, the exact number of available numbers of MRI reading at each time point is shown.

Baseline characteristics of the 155 patients with repeated MRI at 5 years were comparable with the 459 patients with only MRIs at baseline (table 1 ). In the 155 patients with complete 5-year MRI readings, 81 (52\%) were female with a mean age of 33.5 (SD 8.9) years.

A
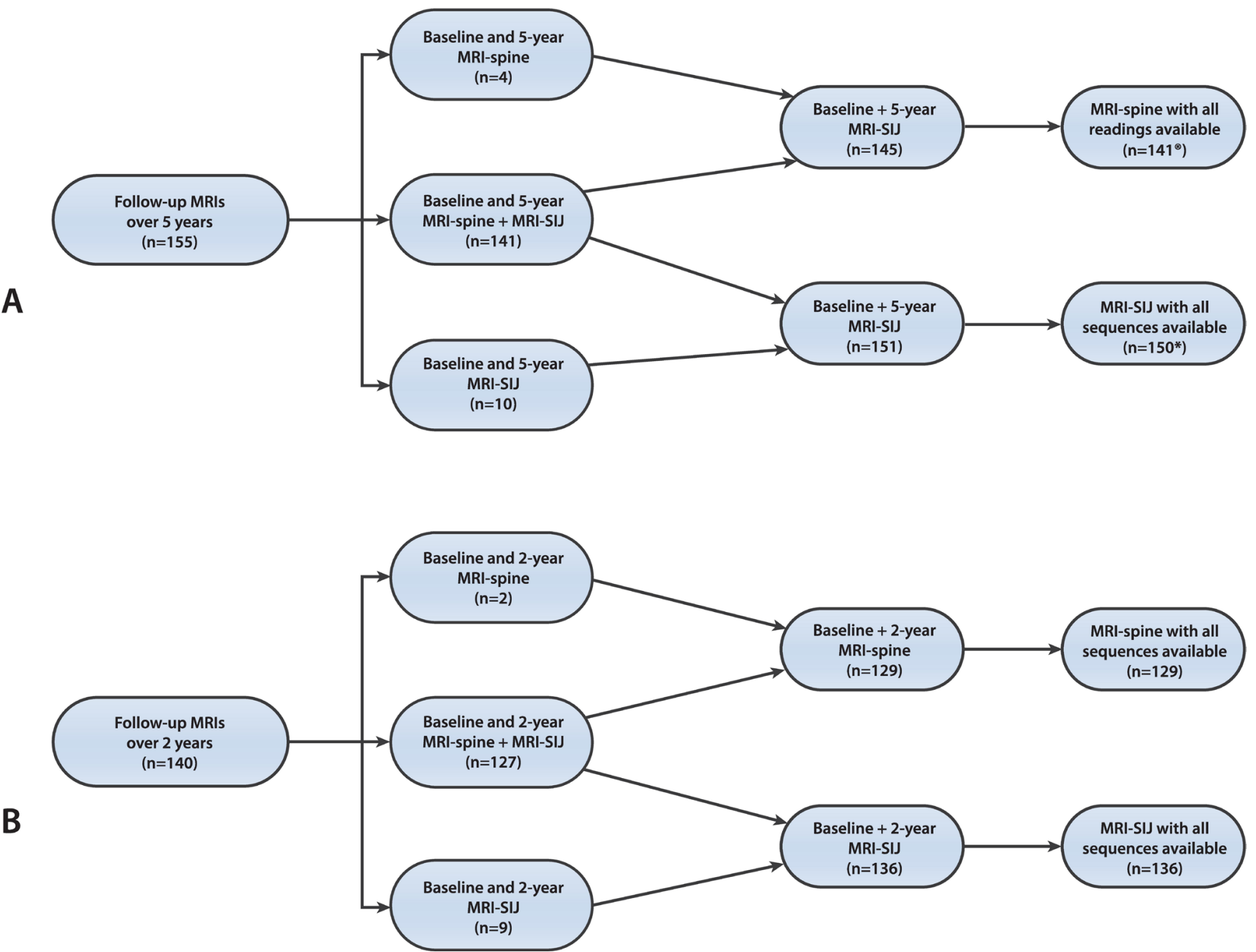

Figure 1 Overview of follow-up MRI over 5 years (A) and 2 years (B) of either the SIJ, spine or both. Reading of T1-weighted sequence is present from all three readers. ${ }^{*}$ One missing MRI-SIJ short tau inversion recovery sequence in MRI. SIJ, sacroiliac joint. 
Table 1 Baseline characteristics of patients $(\mathrm{N}=614)$ in the Devenir des Spondyloarthropathies Indifférenciées Récentes cohort with baseline MRI reading split according to the availability of 5-year MRI imaging of the SIJ and/or spine

\begin{tabular}{|c|c|c|}
\hline & $\begin{array}{l}\text { Patients with follow-up MRI* } \\
(n=155)\end{array}$ & $\begin{array}{l}\text { Patients without follow-up MR } \\
(n=459)\end{array}$ \\
\hline Age at baseline (years) & $33.5(8.9)$ & $33.9(8.7)$ \\
\hline Female gender, $\mathrm{n}(\%)$ & $81 / 155(52)$ & $248 / 459(54)$ \\
\hline Symptom duration (years) & $1.4(0.8)$ & $1.6(0.9) \dagger$ \\
\hline Peripheral arthritis, $\mathrm{n}(\%)$ & $36 / 153(24)$ & $103 / 459(22)$ \\
\hline Uveitis, n (\%) & $12 / 155(7.7)$ & $45 / 459(10)$ \\
\hline Enthesitis, n (\%) & $91 / 155(59)$ & $258 / 459(56)$ \\
\hline Dactylitis, n (\%) & 22/155 (14) & $64 / 458(14)$ \\
\hline IBD, n (\%) & $8 / 155(5.2)$ & $25 / 459(6)$ \\
\hline Psoriasis, $\mathrm{n}(\%)$ & $30 / 155(19)$ & 77/459 (17) \\
\hline Good response to NSAIDs, $\mathrm{n}(\%)$ & $136 / 155(88)$ & $397 / 455(87)$ \\
\hline Positive family history, n (\%) & $64 / 145(44)$ & $191 / 435(44)$ \\
\hline HLA-B27 positive, n (\%) & $98 / 155(63)$ & $269 / 458(59)$ \\
\hline Elevated CRP ( $\geq 6 \mathrm{mg} / \mathrm{L}), \mathrm{n}(\%)$ & $41 / 148(28)$ & $133 / 445(30)$ \\
\hline Radiographical sacroilitis baseline (mNY), n (\%) & $21 / 150(14)$ & $65 / 446(15)$ \\
\hline Meeting the ASAS axSpA criteria & $102 / 154(66 \%)$ & $276 / 448(62 \%)$ \\
\hline ASDAS-CRP† & $2.7(0.9)$ & $2.6(1.0)$ \\
\hline BASFI† (0-10) & $3.1(2.4)$ & $3.0(2.2)$ \\
\hline Use of NSAIDs, $n$ (\%) & $147 / 155(95)$ & $424 / 459(92)$ \\
\hline Use of bDMARDs at baseline, $\mathrm{n}(\%)$ & $0 / 155(0)$ & 0/459 (0) \\
\hline
\end{tabular}

All numbers in the table are mean (SD) unless indicated otherwise.

${ }^{*}$ Patients with both baseline and 5-year MRI available of either the SIJ, spine or both.

$\dagger<5 \%$ missing data.

ASAS, Assessment of Spondyloarthritis International Society; ASDAS, Ankylosing Spondylitis Disease Activity Score; axSpA, axial spondyloarthritis; BASFI, Bath Ankylosing Spondylitis Functional Index; bDMARD, biological disease-modifying antirheumatic drug; CRP, C reactive protein; HLA-B27, human leucocyte antigen; IBD, inflammatory bowel disease; mNY, modified New York; NSAID, non-steroidal antiinflammatory drug; SIJ, sacroiliac joint.

The mean symptom duration at baseline was 1.4 (SD $0.8)$ years, and $98(63 \%)$ were human leucocyte antigen B27 positive. Sixty-six per cent of patients met the ASAS classification criteria, and none of the patients were using biological disease-modifying antirheumatic drugs (bDMARDs) at baseline.

\section{Reliability of MRI scores}

Overall, the ICCs for status scores and mean change of sacroiliac BME were good: baseline, 0.9 (95\% CI 0.8 to 0.9 ); 2 years, 0.9 (95\% CI 0.8 to 0.9 ); 5 years, 0.8 (95\% CI 0.7 to 0.9$)$; and 5 -year mean change: 0.8 (95\% CI 0.8 to $0.9)$. The ICCs for spinal BME were moderate and similar over the scoring methods: baseline Berlin, 0.7 (95\% CI 0.6 to 0.8 ); baseline SPARCC, 0.7 (95\% CI 0.6 to 0.8 ); 2-year Berlin, 0.6 (95\% CI 0.5 to 0.7); 2-year SPARCC, $0.6(95 \%$ CI 0.6 to 0.7$)$; 5 -year Berlin, 0.6 (95\% CI 0.5 to 0.6 ); 5 -year SPARCC, 0.6 (95\% CI 0.5 to 0.6 ); 5 -year mean change Berlin, 0.6 (95\% CI 0.5 to 0.7 ); and 5-year mean change SPARCC, 0.6 ( $95 \%$ CI 0.6 to 0.7 ).

In the supplementary data, the individual reader scores of both sacroiliac (online supplementary table S1) and spinal structural lesions (including spinal bone spurs) (online supplementary table S2) are presented in detail with corresponding ICC values. The overall ICCs for status scores for sacroiliac structural lesions on MRI were moderate (erosions) to good (fatty lesions and lesions combined) at 2 and 5 years (range 0.5-0.9). The ICCs of mean change scores for sacroiliac structural lesions over 5 years were poor (erosions) to moderate (fatty lesion and lesions combined) (range 0.3-0.6). Status scores for spinal lesions on MRI had poor (erosions, bone spurs, to moderate (fatty lesions and lesions combined) ICC values (range $0.0-0.7$ ); ICCs of the different spinal change scores were poor (range 0.0-0.3).

\section{Change in MRI-SIJ lesions over 5 years of follow-up}

Table 2 presents the status scores with the mean change over time for sacroiliac BME and structural lesions at baseline and at 2 and 5 years. Over 5 years, a decrease in mean SPARCC score of -1.4 (SD 6.5) ( $\mathrm{p}=0.009$, baseline vs 5 years) was observed. After 5 years the percentage of patients meeting the ASAS definition of a positive MRI had decreased by $7.3 \%$ from $29.3 \%$ to $22.0 \%$.

Over 5 years (ie, comparing the 5-year score with the baseline score), the mean number of erosions on MRI-SIJ increased by 0.2 (SD 1.4) $(\mathrm{p}=0.085)$; the mean number of fatty lesions increased by 0.8 (SD 2.2) $(\mathrm{p}<0.001)$; and the 
Table 2 BME and structural lesions on MRI-sacroiliac joint of patients from the Devenir des Spondyloarthropathies Indifférenciées Récentes cohort over 5 years of follow-up

\begin{tabular}{|c|c|c|c|c|c|}
\hline & $\begin{array}{l}\text { Baseline } \\
\text { mean (SD) } \\
(n=150)^{\star}\end{array}$ & $\begin{array}{l}2 \text { years' } \\
\text { mean (SD) } \\
(n=136)\end{array}$ & $\begin{array}{l}5 \text { years' } \\
\text { mean }(S D) \\
(n=150)^{\star}\end{array}$ & $\begin{array}{l}\text { Change over } 5 \text { years' } \\
\text { mean (SD) }\end{array}$ & $\mathbf{P}$ valuet \\
\hline \multicolumn{6}{|l|}{ BME lesions (scores) } \\
\hline Mean SPARCC score $\ddagger(0-72)$ & $3.8(7.2)$ & $2.8(5.8)$ & $2.4(4.7)$ & $-1.4(6.5)$ & 0.009 \\
\hline \multicolumn{6}{|l|}{ Structural lesions (scores) } \\
\hline Mean number of erosions $\ddagger(0-40)$ & $1.0(1.9)$ & $1.1(2.0)$ & $1.2(2.1)$ & $0.2(1.4)$ & 0.085 \\
\hline $\begin{array}{l}\text { Mean number of fatty lesions and/or } \\
\text { erosions } \\
(0-80)\end{array}$ & $2.1(3.9)$ & $2.8(5.0)$ & $3.1(5.1)$ & $1.0(2.6)$ & $<0.001$ \\
\hline $\begin{array}{l}\text { Mean total number of lesions } \ddagger \S \\
(0-144)\end{array}$ & $2.6(4.5)$ & $3.3(6.2)$ & $3.9(6.5)$ & $1.3(3.1)$ & $<0.001$ \\
\hline
\end{tabular}

\begin{tabular}{|c|c|c|c|c|c|c|}
\hline & $\begin{array}{l}\text { Baseline } \\
n(\%) \\
(n=150)^{*}\end{array}$ & $\begin{array}{l}2 \text { years } \\
n(\%) \\
(n=136)\end{array}$ & $\begin{array}{l}5 \text { years } \\
n(\%) \\
(n=150)^{*}\end{array}$ & $\begin{array}{l}\text { Positive } \\
\text { change over } \\
5 \text { years } \\
\text { n (\%) }\end{array}$ & $\begin{array}{l}\text { Negative } \\
\text { change } \\
\text { over } 5 \\
\text { years } \\
\mathrm{n}(\%) \\
\end{array}$ & $\begin{array}{l}\text { Net change } \\
\text { n (\%) }\end{array}$ \\
\hline \multicolumn{7}{|l|}{ BME lesions (cut-off) } \\
\hline \multirow[t]{2}{*}{ ASAS definition* } & 44 (29.3) & $30(22.1)$ & $32(22.0)$ & $10(6.7)$ & $21(14.0)$ & $-11(-7.3)$ \\
\hline & $\begin{array}{l}\text { Baseline } \\
\text { n (\%) }\end{array}$ & $\begin{array}{l}2 \text { years } \\
n(\%) \\
(n=136)\end{array}$ & $\begin{array}{l}5 \text { years } \\
\text { n (\%) }\end{array}$ & $\begin{array}{l}\text { Positive } \\
\text { change over } \\
5 \text { years } \\
\text { n (\%) }\end{array}$ & $\begin{array}{l}\text { Negative } \\
\text { change } \\
\text { over } 5 \\
\text { years } \\
\mathrm{n}(\%)\end{array}$ & $\begin{array}{l}\text { Net change } \\
\text { n (\%) }\end{array}$ \\
\hline \multicolumn{7}{|l|}{ Structural lesions (cut-offs) } \\
\hline$\geq 3$ erosions & $20(13.3)$ & $21(15.4)$ & $21(13.9)$ & $8(5.3)$ & $7(4.6)$ & $1(0.7)$ \\
\hline$\geq 3$ fatty lesions & 20 (13.3) & $26(19.1)$ & $32(21.2)$ & $12(8.0)$ & $0(0.0)$ & $12(8.0)$ \\
\hline$\geq 5$ fatty lesions and/or erosions & $23(15.2)$ & $32(23.5)$ & 33 (21.9) & $12(8.0)$ & $2(1.3)$ & $10(6.6)$ \\
\hline
\end{tabular}

${ }^{*}$ Missing MRI short tau inversion recovery sequence in one case at 5 years.

†Paired samples t-test comparing baseline versus 5 years.

$\ddagger$ Mean of three readers.

§Fatty lesions, erosions, sclerosis and partial ankylosis/total ankylosis.

IAgreement of $\geq 2$ out of 3 readers.

ASAS, Assessment of Spondyloarthritis International Society; BME, bone marrow oedema; SPARCC, Spondyloarthritis Research Consortium of Canada.

mean number of fatty lesions and/or erosions increased by $1.0 \quad(\mathrm{SD} 2.6) \quad(\mathrm{p}<0.001)$. Sacroiliac sclerosis and (partial) ankylosis were rare at both baseline and 5 years (data not shown) and contributed little to the observed mean increase in the total number of structural lesions of $1.3(\mathrm{SD} 3.1)(\mathrm{p}<0.001)$.

Over 5 years, the net increase to $\geq 3$ erosions was $0.7 \%$; the net increase to $\geq 3$ fatty lesions was $8.0 \%$; and the net increase to $\geq 5$ fatty lesions and/or erosions was $6.6 \%$.

\section{Changes in MRI-spine lesions over 5 years of follow-up}

Table 3 presents the status scores with the mean change over time for spinal BME and structural lesions at baseline and at 2 and 5 years. Over 5 years, non-significant increases in the mean Berlin score of 0.1 (SD 1.7) $(\mathrm{p}=0.43)$ and in the s-SPARCC score of 0.3 (SD 4.6) $(p=0.41)$ were observed. After 5 years, the percentage of patients meeting the ASAS definition of a positive MRIspine ( $\geq 3 \mathrm{BME}$ lesions) had increased by $2.8 \%$ from $4.8 \%$ to $7.6 \%$, and the percentage of patients with at least five BME lesions had decreased by $0.7 \%$ from $3.4 \%$ to $2.8 \%$

Over 5 years, the mean number of erosions remained 0.0 (SD 0.2) $(\mathrm{p}=1.0)$; the mean number of bone spurs increased by 0.1 (SD 0.3) $(\mathrm{p}=0.012)$; the mean number of fatty lesions increased by $0.1(\mathrm{SD} 0.4)(\mathrm{p}=0.001)$; the mean number of fatty lesions and/or erosions increased by $0.2(\mathrm{SD} 0.5) \quad(\mathrm{p}<0.001)$; and the mean total number of structural lesions increased by 0.2 (SD 0.6) $(\mathrm{p}<0.001)$. Spinal sclerosis and ankylosis were rare at both baseline and 5 years (data not shown). 
Table 3 BME and structural lesions on MRI-spine of patients from the Devenir des Spondyloarthropathies Indifférenciées Récentes cohort over 5 years of follow-up

\begin{tabular}{|c|c|c|c|c|c|}
\hline & $\begin{array}{l}\text { Baseline mean } \\
\text { (SD) }(n=145)\end{array}$ & $\begin{array}{l}2 \text { years' } \\
\text { mean (SD) } \\
(n=129)\end{array}$ & $\begin{array}{l}5 \text { years' } \\
\text { mean (SD) } \\
(n=145)\end{array}$ & $\begin{array}{l}\text { Change over } 5 \text { years } \\
\text { mean (SD) }\end{array}$ & P value* \\
\hline \multicolumn{6}{|l|}{ BME lesions (scores) } \\
\hline Mean Berlin score† (0-69) & $0.6(1.5)$ & $0.6(1.2)$ & $0.7(1.3)$ & $0.1(1.7)$ & 0.43 \\
\hline Mean 23 DVU SPARCC score† (0-414) & $1.6(4.1)$ & $1.7(3.3)$ & $1.9(3.7)$ & $0.3(4.6)$ & 0.41 \\
\hline \multicolumn{6}{|l|}{ Structural lesions (scores) } \\
\hline Mean number of erosions $† \ddagger(0-92)$ & $0.1(0.2)$ & $0.1(0.2)$ & $0.1(0.2)$ & $0.0(0.2)$ & 1.000 \\
\hline Mean number of bone spur†‡ (0-92) & $0.1(0.3)$ & $0.2(0.3)$ & $0.2(0.4)$ & $0.1(0.3)$ & 0.012 \\
\hline Mean number of fatty lesions $† \ddagger(0-92)$ & $0.2(0.7)$ & $0.3(0.8)$ & $0.4(1.0)$ & $0.1(0.4)$ & 0.001 \\
\hline $\begin{array}{l}\text { Mean number of fatty lesions } \\
\text { and / or erosions }(0-184) \dagger \ddagger\end{array}$ & $0.3(0.8)$ & $0.3(1.0)$ & $0.4(1.1)$ & $0.2(0.5)$ & $<0.001$ \\
\hline Mean total number of lesions§†‡ (0-322) & $0.4(0.9)$ & $0.5(1.1)$ & $0.6(1.2)$ & $0.2(0.6)$ & $<0.001$ \\
\hline
\end{tabular}

DVU, discovertebral unit.

\begin{tabular}{|c|c|c|c|c|c|c|}
\hline & $\begin{array}{l}\text { Baseline } \\
n(\%) \\
(n=145)\end{array}$ & $\begin{array}{l}2 \text { years } \\
n(\%)(n=129)\end{array}$ & $\begin{array}{l}5 \text { years } \\
n(\%) \\
(n=145)\end{array}$ & $\begin{array}{l}\text { Positive } \\
\text { change over } \\
5 \text { years } \\
\mathrm{n}(\%)\end{array}$ & $\begin{array}{l}\text { Negative } \\
\text { change over } \\
5 \text { years } \\
\text { n (\%) }\end{array}$ & $\begin{array}{l}\text { Net change } \\
\mathrm{n}(\%)\end{array}$ \\
\hline \multicolumn{7}{|l|}{ BME lesions (cut-off) } \\
\hline ASAS $\geq 3$ BME lesions & $7(4.8)$ & $9(7.0)$ & $11(7.6)$ & $7(4.8)$ & $3(2.1)$ & $4(2.8)$ \\
\hline \multirow[t]{2}{*}{ 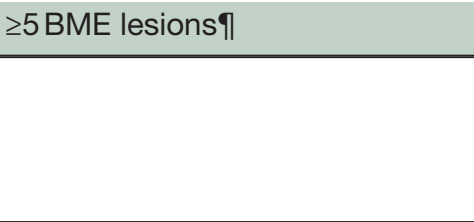 } & $5(3.4)$ & $3(2.3)$ & $4(2.8)$ & $3(2.1)$ & $4(2.8)$ & $-1(-0.7)$ \\
\hline & $\begin{array}{l}\text { Baseline } \\
n(\%)(n=145)\end{array}$ & $\begin{array}{l}2 \text { years } \\
n(\%)(n=129)\end{array}$ & $\begin{array}{l}5 \text { years } \\
n(\%) \\
(n=145)\end{array}$ & $\begin{array}{l}\text { Positive } \\
\text { change over } \\
5 \text { years } \\
\text { n (\%) }\end{array}$ & $\begin{array}{l}\text { Negative } \\
\text { change over } \\
5 \text { years } \\
n(\%)\end{array}$ & $\begin{array}{l}\text { Net change } \\
\text { n (\%) }\end{array}$ \\
\hline \multicolumn{7}{|l|}{ Structural lesions (cut-offs) } \\
\hline$\geq 3$ erosions $\mathbb{1}$ & $0(0.0)$ & $0(0)$ & $0(0.0)$ & $0(0.0)$ & $0(0.0)$ & $0(0.0)$ \\
\hline$\geq 3$ bone spurs $\uparrow$ & $0(0.0)$ & $0(0.0)$ & $0(0.0)$ & $0(0.0)$ & $0(0.0)$ & $0(0.0)$ \\
\hline$\geq 3$ fatty lesions & $1(0.7)$ & $2(1.6)$ & $2(1.4)$ & $1(0.7)$ & $0(0.0)$ & $1(0.7)$ \\
\hline$\geq 5$ fatty lesions & $2(1.4)$ & $1(0.8)$ & $1(0.7)$ & $0(0.0)$ & $1(0.7)$ & $-1(-0.7)$ \\
\hline$\geq 5$ fatty lesions and/or erosions & $2(1.4)$ & $1(0.8)$ & $1(0.7)$ & $0(0.0)$ & $1(0.7)$ & $-1(-0.7)$ \\
\hline
\end{tabular}

*Paired samples t-test comparing baseline versus 5 years.

†Mean of three readers.

$\ddagger$ Missing data from at least one time point and one reader for four cases.

§Fatty lesions, erosions, bone spurs and ankylosis.

ПAgreement of $\geq 2$ out of 3 readers.

ASAS, Assessment of Spondyloarthritis International Society; BME, bone marrow oedema; SPARCC, Spondyloarthritis Research Consortium of Canada.

Over 5 years, the net progression to $\geq 5$ fatty lesions on MRI-spine was $-0.7 \%$.

MRI changes in patients using bDMARDs at 5 years

At 5 years, information on bDMARD (all TNF blockers) usage was available for 145 out of 155 patients with MRI follow-up. At 5 years, 68 of 145 patients were using bDMARDs and $77 / 145$ were not.

Baseline SIJ BMEs were similar (mean SPARCC 3.7 (SD 7.5) vs 3.5 (SD 7.5)), while at 5 years, SIJ BME was lower in patients using bDMARD (mean SPARCC 1.2 (SD 2.3) vs 3.2 (SD 5.8) ( $\mathrm{p}=0.01$ comparing bDMARD vs non-bDMARD users at 5 years)). In all patients, over
5 years, no significant change in spinal BME was seen (mean Berlin 0.1 (SD 1.7) and mean 23 DVU SPARCC 0.3 (SD 4.6)) (table 3). After subdividing these groups in to bDMARD users versus non-users, a similar pattern was seen between the two groups: bDMARD users' mean Berlin was 0.1 and mean 23 DVU SPARCC 0.4 and non bDMARD users Berlin 0.1 and mean 23 DVU SPARCC 0.3 with all changes not statistically significant.

At both baseline and 5 years, the mean total number of structural lesions in both SIJ and spine was similar in patients using bDMARDs and not using bDMARDs (SIJ baseline 2.9 (SD 5.5) vs 2.6 (SD 5.4), SIJ 5 years 3.8 (SD 
7.9 ) vs 4.2 (SD 7.8), spine baseline 0.5 (SD 1.2) vs 0.4 (SD $0.9)$; spine 5 years 1.9 (SD 4.4) vs 2.3 (SD 4.4)).

\section{DISCUSSION}

Over 5years, BME on MRI-SIJ decreased and structural lesions on MRI-SIJ increased significantly in patients with early axSpA. The increase in structural lesions was mostly due to fatty lesions, which led to a small increase in the number of patients with a number of structural lesions with a high specificity for $\operatorname{axSpA}$ (ie, $\geq 5$ fatty lesions and/ or erosions).

In addition, spinal BME remained essentially unchanged, and a statistically significant but (in absolute numbers) very small increase in total spinal structural lesions was observed.

However, the number of patients with a number of structural lesions highly specific for axSpA (ie, $\geq 5$ fatty lesions) also remained low on MRI-spine over time. These results are consistent with previously reported limited radiographical progression in patients from this cohort. ${ }^{1719}$

To our knowledge, these are the first long-term MRI data from an early disease inception cohort. The MRI-SIJ results are consistent with data from clinical trials where, in particular, an increase in fatty lesions was mirrored by a decrease in BME over time. ${ }^{20}{ }^{21}$ However, significant changes in erosions on MRI-SIJ were not observed in the DESIR cohort. This partly contrasts with previous findings from a clinical trial where regression of sacroiliac erosions was reported after initiation of bDMARD therapy. However, patients in this trial had much higher baseline levels of erosions than in our cohort, and strikingly, the decrease in MRI erosions was found using the SPARCC method and not the Berlin method. ${ }^{20}$

As patients using a bDMARD showed the largest decrease in SIJ and spinal BME over 5 years, it is likely that these MRI changes were indeed caused by treatment. However, this requires further investigation, specifically designed for this aim, and will be addressed in future analyses (including taking into account, for instance, confounding by indication). This may have implications for clinical practice. As there is no single feature on imaging that discriminates between axSpA and other conditions characterised by chronic back pain, a diagnosis of early axSpA can be challenging and diagnostic uncertainty is a common problem. This is particularly true for patients suspected of axSpA already receiving TNF blockers (for instance, because of inflammatory bowel disease or uveitis), where it is difficult to know if SIJ BME would have been present if the patient would not have used medication. Moreover, as in the current study, in early disease, the number of patients with net progression to structural lesions with a high specificity for axSpA was limited; diagnostic sensitivity of structural lesions on MRI remained low. Therefore, a repeated MRI in cases of diagnostic uncertainty in the first 5 years of disease to detect progression to a number of structural lesions highly specific (i.e. $\geq 5$ fatty lesions and/or erosions) for axSpA is likely to be of limited value. ${ }^{21}$
Although sometimes useful to rule out other causes of back pain in patients suspected of axSpA, spinal MRI is not routinely used in diagnosis of the disease. ${ }^{6}$ The low percentage of patients having spinal lesions with a high specificity for axSpA at both baseline and over 5 years supports this practice. Overall, the number of both spinal and sacroiliac MRI lesions was lower in our patients with early disease compared with patients included in clinical trials with active disease (with the possible exception of structural lesions in patients with exclusively recent onset of non-radiographical $\operatorname{axSpA}){ }^{22}$

This is relevant not only when interpreting trial data but also when designing clinical trials and, in particular, for trials where longitudinal detection of changes on MRI imaging are relevant outcomes.

A strength of this study is the longitudinal analysis of MRI data from an inception cohort and thus gaining insight in the early phase of axSpA on MRI. In addition, evaluation of structural lesions on MRI was done using multiple readers. However, a clear limitation is the low prevalence of some MRI lesions (eg, bone spurs or spinal erosions) contributing to low ICC values, which made the interpretation of the reliability for these lesions difficult. ${ }^{13}$

Moreover, it is important to emphasise that the patients in this cohort study are more heterogenous than clinical trials patients. For example, meeting the ASAS classification criteria was not a requirement for inclusion and treatment was not standardised. Finally, although baseline characteristics were similar, follow-up MRI was performed in only a limited number of patients in the cohort, that is, in the centres that were part of a group of hospitals in Paris.

Nevertheless, for future studies, these longitudinal data provide the opportunity to study correlations between spinal and sacroiliac BME and subsequent development of structural lesions over time. This may not only present useful prognostic information but may also help in understanding the pathophysiology of axial SpA.

In conclusion, in our cohort in the first 5 years, sacroiliac BME decreased and structural lesions increased significantly in the SIJ. Spinal BME remained similar and structural progression was minimal. The percentage of patients with a net change was low for all active and structural lesions on MRI-SIJ and MRI-spine.

Thus, given the low progression to a number of lesions with high specificity for axSpA, performing a repeated MRI to detect progression of structural lesions in the first 5 years of early axSpA is likely to be of limited value, but these data may be used to study the relationship between SpA-associated MRI abnormalities, including the effect of treatment.

\section{Author affiliations}

${ }^{1}$ Department of Rheumatology, Leiden University Medical Center, Leiden, the Netherlands

${ }^{2}$ NOVA Medical School, Universidade Nova de Lisboa, Lisbon, Portugal ${ }^{3}$ Department of Rheumatology, Cochin Hospital, Assistance Publique- Hôpitaux de Paris, Paris, France

${ }^{4}$ Department of Rheumatology, Henri Mondor Hospital, APHP, and Université Paris Est Créteil, EA, 7379 - EpidermE, F-94010, Créteil, France 
${ }^{5}$ Department of Rheumatology, CHRU de BESANCON, University Teaching Hospital, and Université de Franche-Comté, EA4266 EPILAB, F-25030, Besançon, France

${ }^{6}$ Paris Descartes University, Paris, France

Acknowledgements The DESIR cohort is conducted under the umbrella of the French Society of Rheumatology and Institut National de la Santé et de la Recherche Médicale. The database management is performed within the department of epidemiology and biostatistics (Professor Paul Landais, DIM., Nîmes, France). The authors thank the different regional participating centers: $\mathrm{Pr}$ Maxime Dougados (Paris, Cochin B), Pr André Kahan (Paris, Cochin A), Pr Olivier Meyer (Paris, Bichat), Pr Pierre Bourgeois (Paris, La Pitié Salpetrière), Pr Francis Berenbaum (Paris, Saint Antoine), Pr Pascal Claudepierre (Créteil), Pr Maxime Breban (Boulogne Billancourt), Dr Bernadette Saint-Marcoux (Aulnay-sous-Bois), Pr Philippe Goupille (Tours), Pr Jean-Francis Maillefert (Dijon), Dr Xavier Puéchal, Dr Emmanuel Dernis (Le Mans), Pr Daniel Wendling (Besançon), Pr Bernard Combe (Montpellier), Pr Liana Euller-Ziegler (Nice), Pr Philippe Orcel, Dr Pascal Richette (Paris - Lariboisière), Pr Pierre Lafforgue (Marseille), Dr Patrick Boumier (Amiens), Pr Jean-Michel Ristori, Pr Martin Soubrier (Clermont-Ferrand), Dr Nadia Mehsen (Bordeaux), Pr Damien Loeuille (Nancy), Pr René-Marc Flipo (Lille), Pr Alain Saraux (Brest), Pr Corinne Miceli (Le Kremlin Bicêtre), Pr Alain Cantagrel (Toulouse) and Pr Olivier Vittecoq (Rouen). The authors also thank Unité de Recherche Clinique Centre d'Investigation Clinic Centre Paris for the coordination and monitoring of the study.

Contributors $\mathrm{QM}, \mathrm{AS}$ and $\mathrm{SR}$ performed the statistical analyses. QM and FAvG wrote the first draft of the manuscript. All authors critically interpreted the results, reviewed the draft version and approved the final manuscript.

Funding Devenir des Spondyloarthropathies Indifférenciées Récentes (DESIR) is financially supported by an unrestricted grant from Pfizer. AS is supported by a doctoral grant from 'Fundacão para a Ciência e Tecnologia' (SFRH/ $\mathrm{BD} / 108246 / 2015)$. The DESIR study is conducted as a Programme Hospitalier de Recherche Clinique with Assistance Publique Hopitaux de Paris as the sponsor. The DESIR study is also under the umbrella of the French Society of Rheumatology, which financially supports the cohort. An unrestricted grant from Pfizer has been allocated for the first 10 years.

Competing interests None declared.

Patient consent for publication Not required

Ethics approval The study was reviewed and approved by the ethical committee of the Cochin Hospital Paris, France, 75014 plus each individual study centre. The study was conducted according to good clinical practice guidelines Before inclusion, written informed consent was obtained from all participating patients.

Provenance and peer review Not commissioned; externally peer reviewed.

Data availability statement Data are available upon reasonable request. More information on the DESIR cohort can be found at http://www.lacohortedesir.fr/

Open access This is an open access article distributed in accordance with the Creative Commons Attribution Non Commercial (CC BY-NC 4.0) license, which permits others to distribute, remix, adapt, build upon this work non-commercially, and license their derivative works on different terms, provided the original work is properly cited, appropriate credit is given, any changes made indicated, and the use is non-commercial. See: http://creativecommons.org/licenses/by-nc/4.0/.

ORCID iDs

Alexandre Sepriano http://orcid.org/0000-0003-1954-0229

Anna Molto http://orcid.org/0000-0003-2246-1986

Daniel Wendling http://orcid.org/0000-0002-4687-5780

Desirée van der Heijde http://orcid.org/0000-0002-5781-158X

Floris A van Gaalen http://orcid.org/0000-0001-8448-7407

\section{REFERENCES}

1 Sieper J, Rudwaleit M, Baraliakos X, et al. The assessment of spondyloarthritis International Society (ASAS) Handbook: a guide to assess spondyloarthritis. Ann Rheum Dis 2009;68 Suppl 2:ii1-44.

2 Rudwaleit M, Jurik AG, Hermann K-GA, et al. Defining active sacroiliitis on magnetic resonance imaging (MRI) for classification of axial spondyloarthritis: a consensual approach by the ASAS/ OMERACT MRI group. Ann Rheum Dis 2009;68:1520-7.

3 Rudwaleit M, van der Heijde D, Khan MA, et al. How to diagnose axial spondyloarthritis early. Ann Rheum Dis 2004;63:535-43.

4 de Winter J, de Hooge M, van de Sande M, et al. Magnetic resonance imaging of the Sacroiliac joints indicating sacroiliitis according to the assessment of spondyloarthritis International Society definition in healthy individuals, runners, and women with postpartum back pain. Arthritis Rheumatol 2018;70:1042-8.

5 de Hooge M, van den Berg R, Navarro-Compán V, et al. Patients with chronic back pain of short duration from the space cohort: which MRI structural lesions in the sacroiliac joints and inflammatory and structural lesions in the spine are most specific for axial spondyloarthritis? Ann Rheum Dis 2016;75:1308-14.

6 Ez-Zaitouni Z, Bakker PA, van Lunteren M, et al. The yield of a positive MRI of the spine as imaging criterion in the ASAS classification criteria for axial spondyloarthritis: results from the space and DESIR cohorts. Ann Rheum Dis 2017;76:1731-6.

7 van der Heijde D, Machado P, Braun J, et al. Mri inflammation at the vertebral unit only marginally predicts new syndesmophyte formation: a multilevel analysis in patients with ankylosing spondylitis. Ann Rheum Dis 2012;71:369-73.

8 Baraliakos X, Borah B, Braun J, et al. Long-Term effects of secukinumab on MRI findings in relation to clinical efficacy in subjects with active ankylosing spondylitis: an observational study. Ann Rheum Dis 2016;75:408-12.

9 Dougados M, Etcheto A, Molto A, et al. Clinical presentation of patients suffering from recent onset chronic inflammatory back pain suggestive of spondyloarthritis: the DESIR cohort. Joint Bone Spine 2015;82:345-51.

10 Maksymowych WP, Inman RD, Salonen D, et al. Spondyloarthritis research Consortium of Canada magnetic resonance imaging index for assessment of sacroiliac joint inflammation in ankylosing spondylitis. Arthritis Rheum 2005;53:703-9.

11 Maksymowych WP, Inman RD, Salonen D, et al. Spondyloarthritis research Consortium of Canada magnetic resonance imaging index for assessment of spinal inflammation in ankylosing spondylitis. Arthritis Rheum 2005;53:502-9.

12 Weber U, Lambert RGW, Østergaard M, et al. The diagnostic utility of magnetic resonance imaging in spondylarthritis: an international multicenter evaluation of one hundred eighty-seven subjects. Arthritis Rheum 2010;62:3048-58.

13 Lukas C, Braun J, van der Heijde D, et al. Scoring inflammatory activity of the spine by magnetic resonance imaging in ankylosing spondylitis: a multireader experiment. J Rheumatol 2007;34:862-70.

14 Braun J, Baraliakos X, Golder W, et al. Magnetic resonance imaging examinations of the spine in patients with ankylosing spondylitis, before and after successful therapy with infliximab: evaluation of a new scoring system. Arthritis Rheum 2003;48:1126-36.

15 Hermann K-GA, Baraliakos X, van der Heijde DMFM, et al. Descriptions of spinal MRI lesions and definition of a positive MRI of the spine in axial spondyloarthritis: a consensual approach by the ASAS/OMERACT MRI study Group. Ann Rheum Dis 2012;71:1278-88.

16 Østergaard Met al. Structural lesions detected by magnetic resonance imaging in the spine of patients with spondyloarthritis - definitions, assessment system, and reference image set. $J$ Rheumatol 2009;84:18-34.

17 Dougados M, Sepriano A, Molto A, et al. Sacroiliac radiographic progression in recent onset axial spondyloarthritis: the 5-year data of the DESIR cohort. Ann Rheum Dis 2017;76:1823-8.

18 Koo TK, Li MY. A guideline of selecting and reporting intraclass correlation coefficients for reliability research. J Chiropr Med 2016;15:155-63.

19 Ramiro S, van der Heijde D, Sepriano A, et al. Spinal radiographic progression in early axial spondyloarthritis: five-year results from the DESIR cohort. Arthritis care \& research 2018

20 Pedersen SJ, Poddubnyy D, Sørensen IJ, et al. Course of magnetic resonance Imaging-Detected inflammation and structural lesions in the Sacroiliac joints of patients in the randomized, double-blind, placebo-controlled Danish multicenter study of adalimumab in spondyloarthritis, as assessed by the Berlin and spondyloarthritis research Consortium of Canada methods. Arthritis Rheumatol 2016;68:418-29.

21 Bakker PA, Ramiro S, Ez-Zaitouni Z, et al. Is it useful to repeat $\mathrm{MRI}$ of the sacroiliac joints after three months or one year in the diagnostic process of patients with chronic back pain suspected of axial spondyloarthritis? Arthritis Rheumatol 2018.

22 Maksymowych WP, Wichuk S, Dougados M, et al. Modification of structural lesions on MRI of the sacroiliac joints by etanercept in the EMBARK trial: a 12-week randomised placebo-controlled trial in patients with non-radiographic axial spondyloarthritis. Ann Rheum Dis 2018;77:78-84. 